\title{
Combination of Topical Use of a Thrombin-based Hemostatic Matrix and Tranexamic Acid Does Not Have a Synergic Effect on Reducing Postoperative Blood Loss in Minimally Invasive Total Knee Arthroplasty. A Prospective Randomized Controlled Study
}

Shih-Hsiang Yen

Chang Gung Memorial Hospital Kaohsiung Branch

Po-Chun Lin

Chang Gung Memorial Hospital Kaohsiung Branch

Jun-Wen Wang ( $\square$ wangjw@adm.cgmh.org.tw )

Kaohsiung Chang Gung Memorial Hospital and Chang Gung University College of Medicine https://orcid.org/0000-0001-9879-8521

\section{Research Article}

Keywords: tranexamic acid, thrombin-based hemostatic matrix, total knee arthroplasty, total blood loss, transfusion rate

Posted Date: March 15th, 2021

DOI: https://doi.org/10.21203/rs.3.rs-287762/v1

License: (9) This work is licensed under a Creative Commons Attribution 4.0 International License. Read Full License 


\section{Abstract}

\section{Background}

There is limited information regarding the blood-conservation effect of combined topical tranexamic acid (TXA) and thrombin-based hemostatic matrix (TBHM) in total knee arthroplasty (TKA). This study is to evaluate whether there is synergic effect of combined use of TXA and TBHM to reduce blood loss during TKA.

Material and Methods

Sixty-nine patients (69 knees) who underwent primary TKA were randomly assigned into a TXA group ( $\mathrm{n}=$ 34), who received intra-articular administration of $3 \mathrm{~g}$ of TXA in $60 \mathrm{~mL}$ saline, and a TXA + TBHM group ( $\mathrm{n}$ = 35), who received intra-articular TBHM and TXA $(3 \mathrm{~g})$ in $60 \mathrm{~mL}$ saline after TKA. The primary outcomes were total blood loss (TBL) and postoperative hemoglobin $(\mathrm{Hb})$ level. Secondary outcomes included the transfusion rate and the incidence of venous thromboembolism (VTE).

Results

The mean TBL in the TXA + TBHM group was $678 \pm 203 \mathrm{~mL}$, which was similar to that in the TXA only group at $733 \pm 217 \mathrm{~mL}(p=0.276)$. There were no differences in the postoperative $\mathrm{Hb}$ level between the two groups. The transfusion rate was similar in the TXA + TBHM group and the TXA only group $(2.9 \%$ versus $0 \%, p=0.242$ ). No patients in either group developed VTE within 3 months.

Conclusions

Our prospective randomized controlled study did not show a synergic blood-conservation effect of combined use of topical TBHM and TXA in patients undergoing TKA. Further investigation with a larger sample size may be required.

Trial registration: ClinicalTrials.gov, NCT03328832. Registered Oct 30 2017, http://clinicaltrials.gov/ct/show/NCT03328832?order=1

\section{Introduction}

Total knee arthroplasty (TKA) is a common and effective procedure for end-stage arthritis of the knee; however, this procedure is associated with substantial blood loss[1-3] and thromboembolic complications[4-6]. Increased postoperative bleeding around the knee may result in increased pain, hematoma, a decreased range of motion, wound infection and anemia[7-10]. Anemia carries a potential risk in patients receiving major surgery who have a history of cardiopulmonary disease[11-13]. Furthermore, chemoprophylaxis to decrease the risk of venous thromboembolism (VTE) after TKA may enhance postoperative bleeding $[14,15]$. Therefore, a sophisticated modality is required to minimize postoperative bleeding in conjunction with decreasing the incidence of VTE in TKA patients. 
Tranexamic acid (TXA), an inhibitor of fibrinolysis, was reported to be effective for blood conservation after TKA when administered intravenously or topically to the knee joint during surgery[16-20].

Theoretically, topical application during TKA will be safer in terms of thromboembolic risk than systemic administration. In a prospective randomized study, Wong et al. reported a lower total blood loss (TBL) with the use of $3 \mathrm{~g}$ of TXA topically than with a placebo $(1167 \mathrm{~mL}$ versus $1610 \mathrm{~mL}, \mathrm{p}<0.017)$ in standard TKA patients[21]. Low-molecular-weight heparin was administered routinely in this study for thromboprophylaxis. However, for aged patients with or without cardiopulmonary disease, a postoperative blood loss of one liter or more remains a concern with regards to a higher risk of postoperative complications than in patients with a lower postoperative blood loss. A thrombin-based hemostatic agent (TBHM), is a combination of a bovine-derived gelatin matrix, functioning as an adhesive and sealant, and a chemical component, human-derived thrombin. By blending these components, the mixture may act as a hemostasis and sealing agent and reduce bleeding in the surgical field[22]. TBHM has been reported to be effective in reducing blood loss in many operations, including thyroid[23], cardiac[22] and spine surgery[24]; however, its blood-conservation effect in primary TKA is still controversial[25-28]. Recently, we reported equal efficacies of TXA when applied systemically and topically in the knee joint in terms of blood conservation in TKA patients (mean blood loss $921 \mathrm{~mL} \pm 252$ $\mathrm{mL}$ versus $795 \mathrm{~mL} \pm 231 \mathrm{~mL}, \mathrm{p}=0.197$ )[29]. We considered that application of a combination of topical TXA and TBHM to the knee joint may result in a synergetic effect in terms of reduction of postoperative blood loss after TKA. If this is true, the primary TKA procedure will be made safer with fewer complications in elderly patients. Therefore, this study to determine whether a single TXA injection intraarticularily or a combination of TXA and TBHM given intra-articularily is more effective in reducing blood loss in minimally-invasive TKA patients; and whether postoperative complications are reduced with the addition of TBHM during surgery.

\section{Patients And Methods}

The sample size was calculated based upon the study of Suarez et al., who conducted a prospective randomized trial to calculate the perioperative blood loss after total knee arthroplasty[28]. Assuming a mean difference in TBL of $225 \mathrm{~mL}$ or greater between the two groups, in order to obtain a substantial power of 0.90 and an alpha error of $0.05,30$ patients would be required in each group. In consideration of an estimated $10 \%$ of patients who would be lost to follow-up, and $5 \%$ who would have incomplete data, 70 patients were enrolled in this study.

Between September 2017 and September 2018, a consecutive series of 125 patients who underwent unilateral primary minimally-invasive TKA were assessed in terms of their eligibility for inclusion for this study. The inclusion criteria were patients who were between 50 and 75 years of age or older who had end-stage arthritis of the knee and underwent unilateral primary minimally-invasive TKA. The exclusion criteria were as follows: patients with a history of ischemic heart disease or stroke; risk of VTE not amenable to TXA administration; preoperative hemoglobin level less than $11 \mathrm{~g} / \mathrm{dL}$; history of infection or intra-articular fracture of the affected knee; coagulopathy (platelets $<10^{5} / \mathrm{mm}^{3}$, prothrombin time (PT), 
activated partial thrombin time (APTT), international normalized ration of PT (INR) > 1.4); renal function deficiency (glomerular filtration rate $<30 \mathrm{~mL} / \mathrm{min} / 1.73 \mathrm{~m}^{2}$ ), which is contraindicated for chemical VTE prophylaxis; lifelong anticoagulant therapy; and allergies to TXA, TBHM or rivaroxaban. All patients were instructed to withhold aspirin, antiplatelet agents and anticoagulants for at least 7 days prior to surgery. We excluded 35 patients based on the exclusion criteria; in addition, eight patients did not withhold antiplatelet drugs or anticoagulants 7 days before surgery, and 12 other patients declined to participate in the study. Therefore, 70 patients were enrolled in total. Patients were randomly assigned into 2 groups, a TXA group and a TXA + TBHM group, by an independent research assistant using a computer-generated method and by operation date sequence. The clinical investigators were blind to the randomization and allocation of all patients until the complete data had been collected. One patient in the TXA group dropped out of the study due to incomplete data; therefore, 34 patients in the TXA group and 35 patients in the TBHM + TXA group had complete data for analysis (Fig. 1). The preoperative characteristics of the patients, including age, gender, body mass index (BMI), preoperative Hb level, Hct, PT, APTT, platelet count, and American Society of Anesthesiologists (ASA) grade[30], were compared between the two groups (Table 1).

Table 1

Details of the patients

\begin{tabular}{|c|c|c|c|}
\hline Characteristics & $\begin{array}{l}\text { TBHM + TXA } \\
(\mathrm{N}=35)\end{array}$ & $\begin{array}{l}\text { TXA } \\
(\mathrm{N}=34)\end{array}$ & $P$ value \\
\hline Age(yr)(SD;range) & $69.26(5.88 ; 59-79)$ & $67.47(4.00 ; 60-74)$ & 0.144 \\
\hline $\mathrm{BMI}\left(\mathrm{kg} / \mathrm{m}^{2}\right)$ & $28.69(3.77 ; 20.1-34.8)$ & $27.44(4.44 ; 13.3-37.4)$ & 0.211 \\
\hline BMI $\left(\mathrm{kg} / \mathrm{m}^{2}\right)>30$ & $13 / 35(37.1 \%)$ & $7 / 34(20.6 \%)$ & 0.130 \\
\hline Women(\%) & $24 / 35(68.6 \%)$ & 29/34 (85.3\%) & 0.100 \\
\hline ASA - 1 & $0 / 35(0.0 \%)$ & $0 / 35(0.0 \%)$ & 0.947 \\
\hline ASA - 2 & $27 / 35(77.1 \%)$ & $26 / 34(76.5 \%)$ & 0.072 \\
\hline ASA - 3 & $8 / 35(22.9 \%)$ & $8 / 34(23.5 \%)$ & 0.106 \\
\hline PT & $10.44(0.60 ; 10-12)$ & $10.21(0.43 ; 9-11)$ & 0.167 \\
\hline APTT & $28.59(1.96 ; 24.7-31.9)$ & $27.65(2.73 ; 22.1-33.2)$ & 0.213 \\
\hline Preoperative $-\mathrm{Hb}(\mathrm{g} / \mathrm{dl})$ & $13.79(1.39 ; 11.1-18.5)$ & $13.39(0.85 ; 11.4-15.0)$ & 0.914 \\
\hline Preoperative- Hct (\%) & $41.17(3.46 ; 35.2-53.1)$ & $40.28(2.25 ; 34.8-43.7)$ & \\
\hline Platelet count (10000/L) & $250.34(80.13 ; 100-455)$ & 248.59(52.31;175-394) & \\
\hline
\end{tabular}

Continuous data are presented as mean (standard deviation range) TBHM: thrombin-based hemostatic matrix TXA: tranexamic acid SD: standard deviation, BMI: Body mass index, ASA: American Society of Anesthesiologists, PT: Prothrombin time, APTT: Activated partial thromboplastin time. 


\section{Surgical Technique}

All total knee surgeries were performed or supervised by the same senior orthopedic surgeon (JWW), who has extensive experience of primary knee replacement, using a mini-mid vastus approach according to Haas et al[31]. under general anesthesia. The procedure was previously described as follows: "The skin incision was made along the medial border of the mid-to-distal tubercle and the vastus medialis oblique muscle was split approximately $2 \mathrm{~cm}$ in line with its fibers from the superior medial border of the patella." A pneumatic tourniquet was inflated to a pressure of $300 \mathrm{mmHg}$ before the incision and deflated at the end of surgery after skin closure. Routine hemostasis was achieved in all patients by electrocoagulation of blood vessels during surgery. All TKAs were cemented using the same prosthesis (NexGen, Legacy, Posterior-Stabilized Prosthesis; Zimmer, Warsaw, IN, USA). Intra-medullary guidance was used for femoral cutting and an extra-medullary guidance system was used for tibial cutting. The femoral canal was routinely sealed with a bone plug taken from the resected femoral condyle. Two intra-articular drainage tubes were placed in the knee joint and connected to a vacuum bag, and both drains were removed on the afternoon of postoperative day (POD) 1. The volume of drained blood was recorded each day.

Patients in the TXA group received an intra-articular injection of $3 \mathrm{~g}(30 \mathrm{~mL})$ TXA (Transamin $100 \mathrm{mg} / \mathrm{mL}$; China Chemical and Pharmaceutical Co, Taiwan) in $60 \mathrm{~mL}$ saline via the drain after wound closure. Patients in the TXA+ TBHM group received $5 \mathrm{~mL}$ Floseal ${ }^{\circledR}$ (Baxter, Deerfield, IL, USA) intra-articularly, which was applied to the exposed bone surfaces after femoral and tibial cutting and soft tissue release, as well as the bleeding points of the soft tissue and the pinhole of the tibial condyle after cementing the implant and before insertion of the tibial polyethylene liner. Manual compression of the TBHM for 2 minutes on the bone surface or soft tissue using wet gauze was performed routinely. Intra-articular injection of $3 \mathrm{~g}$ TXA in $60 \mathrm{~mL}$ saline was then administered via the drain after wound closure. The drain tubes were routinely clamped for one hour after surgery then released for open drainage. Partial compressions of the vacuum bag were performed postoperatively for 12 hours in all patients, followed by full compression. Intravenous prophylactic antibiotic therapy consisting of $1 \mathrm{~g}$ Cefazolin preoperatively followed by $1 \mathrm{~g}$ every 8 hours for 3 doses postoperatively was administered routinely in all patients. Standard VTE prophylaxis was prescribed in all patients by oral intake of rivaroxaban (Xarelto, Bayer Shering Pharma AG, Wuppertal, Germany) 10mg once daily starting on POD 1 for 14 doses. No other modalities such as compression devices of the leg or foot pumps were used.

The primary outcomes measured were the calculated total blood loss (TBL) and the Hb level on POD 1, 2 and 3. The blood volume was assumed to have normalized on the third postoperative day. TBL was calculated according to the method of Nadler et al[32]. as the maximum postoperative drop in $\mathrm{Hb}$ level adjusted for weight and height of the patient. The formula can be summarized as: Total blood loss (TBL) $=$ Total blood volume X (maximum reduction in $\mathrm{Hb}$ level/mean $\mathrm{Hb}$ level) + volume transfused.

The secondary outcomes measured were the rate of postoperative blood transfusion and the rate of complications, including deep-vein thrombosis (DVT), pulmonary embolism (PE), wound infections, hematoma, and superficial skin necrosis, in addition to length of hospital stay. The trigger for allogeneic 
transfusion of red blood cells was set at a $\mathrm{Hb}$ level of $<8 \mathrm{~g} / \mathrm{dL}$ in the general population or a $\mathrm{Hb}$ level of $<$ $9 \mathrm{~g} / \mathrm{dL}$ in patients with cardiopulmonary disease. The number and rate of blood transfusions were recorded in all patients.

All patients were followed-up at the orthopedic clinic 2, 6 and 12 weeks after surgery. All wound complications, including hematoma, infection, superficial skin necrosis and blisters, as well as leg edema, were recorded. DVT was suspected if the circumference of the operated limb $15 \mathrm{~cm}$ above or below the knee level had increased by $>3 \mathrm{~cm}$ as compared with the opposite limb, associated with calf tenderness and tightness[33]. Ascending venography of the limb was performed where necessary using the Ribinov and Poulin technique[34]. Computed tomography (CT) of the chest was performed if PE was suspected.

\section{Statistical analysis}

The Mann-Whitney $\mathrm{U}$ test was used to determine differences between the two groups in the distribution of demographic and preoperative clinical data. Descriptive data (including gender and ASA grade) were compared between the two groups using the chi-square test or Fisher's exact test. Intention-to-treat analysis was performed in patients who underwent the planned surgery, had taken the study drugs, and had undergone venographic examination to assess thromboembolism.

The independent t-test was used to determine differences in the TBL and transfusion rate between the TXA group and the TXA + TBHM group. The Mann-Whitney $U$ test was used to determine differences in the length of hospital stay, postoperative $\mathrm{Hb}$ drop and blood loss via drainage between the two groups. Descriptive data including safety outcomes, wound complications, and blood transfusion rate in the TXA and the TXA + TBHM group were compared using the chi-square test or Fisher's exact test. All statistical analyses were performed using the Statistical Package for Social Sciences (version 22; SPSS Inc., Chicago, IL, USA).

\section{Results}

The preoperative characteristics of the patients, including age, gender, BMI, preoperative $\mathrm{Hb}$ level, Hct, PT, APTT, platelet count and ASA grade, were all similar in the two groups (Table 1).

The mean TBL in the TXA + TBHM group was $678 \pm 203 \mathrm{~mL}(203-1150 \mathrm{~mL})$, which was similar to that in the TXA group at $733 \pm 217 \mathrm{~mL}(406-1246 \mathrm{~mL}, p=0.276)$. There were no differences in the $\mathrm{Hb}$ level on POD $1(12.46 \pm 1.56 \mathrm{~g} / \mathrm{dL}$ versus $12.12 \pm 1.01 \mathrm{~g} / \mathrm{dL})$, POD $2(11.59 \pm 1.51 \mathrm{~g} / \mathrm{dL}$ versus $11.20 \pm 0.82 \mathrm{~g} / \mathrm{dL})$ or POD $3(11.12 \mathrm{~g} / \mathrm{dL}$ versus $10.79 \pm 0.92 \mathrm{~g} / \mathrm{dL})$ between the TXA + TBHM group and the TXA group, respectively (Table 2$)$. The postoperative drainage volume was also similar in the two groups $(239 \pm 112$ $\mathrm{mL}$ versus $263 \pm 94 \mathrm{~mL}, \mathrm{p}=0.342$ ). One patient in the TXA + TBHM group had a transfusion of one unit of red blood cells on POD 1 owing to symptomatic anemia; however, the transfusion rate did not differ between the two groups $(2.9 \%$ versus $0 \%, p=0.242)$. The wound length in full extension and length of hospital stay were similar in the two groups (Table 2), as were the wound complications up to two weeks after surgery, including ecchymosis, swelling due to hematoma, wound-healing problems and infection 
(Table 3). No patient in either group developed DVT or PE within the 3-month follow-up period, and there were no deaths due to any cause in the two groups. No patient in either group needed to return to the operating theatre due to wound complications (Table 3 ).

Table 2

Blood loss and transfusion requirement

\begin{tabular}{|llll|}
\hline Characteristics & $\begin{array}{l}\text { TBHM + TXA } \\
(\mathbf{N}=35)\end{array}$ & $\begin{array}{l}\text { TXA } \\
(\mathbf{N}=34)\end{array}$ & P value \\
\hline Wound lengh in extension $(\mathrm{cm})$ & $8.39(0.90 ; 6.5-10)$ & $8.20(0.91 ; 7.0-10.5)$ & 0.375 \\
Postoperative Hb level day1 $(\mathrm{g} / \mathrm{dl})$ & $12.46(1.56 ; 9.9-17.0)$ & $12.12(1.01 ; 9.3-14.3)$ & 0.287 \\
Postoperative Hb level day2 $(\mathrm{g} / \mathrm{dl})$ & $11.59(1.51 ; 9.5-15)$ & $11.20(0.82 ; 9.0-13.0)$ & 0.188 \\
Postoperative Hb level day3(g/dl) & $11.12(1.43 ; 9.1-15)$ & $10.79(0.92 ; 8.6-12.8)$ & 0.265 \\
Postoperative drainage volume $(\mathrm{mL})$ & $239(112 ; 50-530)$ & $263(94 ; 70-520)$ & 0.342 \\
Blood transfusion (no./total no) $(\%)$ & $1 / 35(2.9 \%)$ & $0 / 34(0.0 \%)$ & 1.000 \\
Total blood loss(mL) & $678(203 ; 238-1150)$ & $733(217 ; 406-1246)$ & 0.276 \\
Length of hospital stay (days) & $4.09(3-5)$ & $4.12(3-5)$ & 0.758 \\
\hline Continuous data are presented as mean $($ standard deviation range) TBHM: thrombin-based & \\
\hline hemostatic matrix TXA: tranexamic acid & & \\
\hline
\end{tabular}


Table 3

Incidence of events for efficacy analysis

\begin{tabular}{|llll|}
\hline Characteristics & $\begin{array}{l}\text { TBHM + TXA } \\
(\mathbf{N}=35)\end{array}$ & $\begin{array}{l}\text { TXA } \\
(\mathbf{N}=34)\end{array}$ & P value \\
\hline Up to POD 14 & $17 / 35(48.6 \%)$ & $15 / 34(44.1 \%)$ & 0.711 \\
Ecchymosis & $0 / 35(0 \%)$ & $1 / 34(2.9 \%)$ & 0.493 \\
Hematoma & $0 / 35(0 \%)$ & $2 / 34(5.9 \%)$ & 0.239 \\
Superficial skin necrosis & $0 / 35(0 \%)$ & $0 / 34(0 \%)$ & 1.000 \\
Wound infection & $0 / 35(0 \%)$ & $0 / 34(0 \%)$ & 1.000 \\
Any deep-vein thrombosis & $0 / 35(0 \%)$ & $0 / 34(0 \%)$ & 1.000 \\
Up to 3 months & $0 / 35(0 \%)$ & $0 / 34(0 \%)$ & 1.000 \\
Pulmonary embolism & $0 / 35(0 \%)$ & $0 / 34(0 \%)$ & 1.000 \\
Any deep-vein thrombosis & $0 / 35(0 \%)$ & $0 / 34(0 \%)$ & 1.000 \\
Return to OR because of wound complication & & & \\
Death & & & \\
\hline Abbreviations; POD: postoperative day TBHM: thrombin-based hemostatic matrix TXA: tranexamic & \\
\hline
\end{tabular}

\section{Discussion}

The results of our prospective randomized controlled trial showed that the postoperative blood loss (678 $\pm 203 \mathrm{~mL}$ versus $733 \mathrm{~mL} \pm 217 \mathrm{~mL}, p=0.276)$ and blood transfusion rate $(2.9 \%$ versus $0 \%, p=0.242)$ were similar in the combined TBHM and topical TXA group and the topical TXA only group. These results showed that there was no synergic effect of adding a hemostatic agent to topical TXA after TKA. The blood-conservation effect of topical application of TXA after conventional TKA was demonstrated in clinical trials[17, 19, 21] and confirmed in a meta-analysis[20]. With regards to minimally-invasive TKA and routine use of postoperative chemoprophylaxis with rivaroxaban, a factor Xa inhibitor, our previous clinical trial showed a TBL of $795 \pm 231 \mathrm{~mL}$ in the topical TXA group[29]. In the current study, the TBL in the TXA only group was $733 \pm 217 \mathrm{~mL}$, which was similar to the previous study. The TBL in the combined TBHM and TXA group was $678 \pm 203 \mathrm{~mL}$, which was slightly lower than the TBL of $733 \pm 217 \mathrm{~mL}$ in the TXA group; however, the difference did not reach statistical significance. The blood-conservation effects of hemostatic agents such as TBHM and Quixil, and their efficacy and safety, have been reported in general surgery[23], neurosurgery[35] and spine surgery[24]; however, controversy exists when applied to hip and knee replacement surgery. Some studies have demonstrated that topical use of TBHM can reduce the Hb drop and TBL in primary TKA[7, 25, 28], while recent studies have reported contradictory results[27, 36,37 . One of the reasons for the differing results may be that the fibrin glue compound used in studies 
in Europe was Quixil (Omrix, Biopharmaceuticals, Belgium), which is composed of dry precipitated fibrinogen, human thrombin and TXA. We considered that fibrin glue containing a dose of TXA (425 mg to $525 \mathrm{mg}$ ) would act as a topical TXA dose, which is effective in reducing blood loss after TKA[38, 39]. If TXA is not added to the hemostatic agent, the blood-conservation effect will not be as obvious as that of Quixil. Another reason for the non-apparent effect on blood loss of topical TBHM in TKA may be the use of a tourniquet. During the TKA procedure, deflation of the tourniquet may cause a cascade of bleeding from bone cuts and soft-tissue release, which accounts for $60 \%$ of TBL after TKA[16]. The reported fibrinsealing of the blood vessels on the bone cuts or soft-tissue stripping may not be effective, or may be minimally-effective, during the bleeding cascade. Our study showed a small trend of a lower blood loss in the TBHM + TXA group as compared with the TXA only group $(678 \pm 203 \mathrm{~mL}$ versus $733 \pm 217 \mathrm{~mL}, \mathrm{p}=$ 0.242). A larger number of patients in each arm may be necessary to show a difference in TBL. There were some limitations of the study. First, the sample size of each group was small; however, in many prospective randomized controlled trials in which the difference in postoperative blood loss after TKA between groups was being assessed, 30 patients in each group has been adequate[16, 18]. Second, the dose of TBHM used in the study was lower $(5 \mathrm{~mL})$ than the $10 \mathrm{~mL}$ used in other studies $[9,25]$; however, because the TBHM used in the study was an adjunctive agent for fibrin sealing of the bleeding surfaces of the bone cuts, we found that the dose of TBHM used was sufficient to cover all the bone surfaces after TKA. Third, there was no control group in the study, the reason for which was that topical use of $3 \mathrm{~g}$ TXA during TKA has been demonstrated to be effective in reducing postoperative blood loss in many clinical trials, as well as a meta-analysis[17, 19-21], and we considered that inclusion of a control group administered saline instead of TXA was unnecessary, as it may have been detrimental to some patients with cardiopulmonary disease.

\section{Conclusions}

Our prospective randomized controlled study did not show a synergic blood-conservation effect of combined use of topical TBHM and TXA in patients undergoing minimally-invasive TKA. Further investigation with a larger sample size is required.

\section{Abbreviations}

TXA: tranexamic acid; TBHM: thrombin-based hemostatic matrix: TKA: total knee arthroplasty; TBL: total blood loss; Hb: hemoglobin; VTE: venous thromboembolism; PT: prothrombin time; APTT: activated partial thrombin time; INR: international normalized ration of PT; BMI: body mass index; ASA: American Society of Anesthesiologists; POD: postoperative day; PE: pulmonary embolism; CT: computed tomography;

\section{Declarations}

Ethics approval and consent to participate 
The protocol was approved by our institutional review board (201601271A0C501, approved on 2017/09/28)

\section{Consent for publication}

Not applicable

\section{Availability of data and materials}

The datasets used and analyzed in the study are available on request to the corresponding author

\section{Funding}

This study was supported by Chang Gung Memorial Hospital(CMRPG8F1691)

\section{Competing interests}

The authors declare that they have no competing interests

\section{Acknowledgement}

We thank Yan Siou, Huang for the assistance with data collection and data analysis.

\section{Authors' contributions}

$\mathrm{SH}$, Yen developed the study design, performed data analysis and writing the manuscript. JW, Wang developed the study design, performed the surgery and interpreted the data. PC, Lin performed data collection. All authors read and approved the final manuscript.

\section{Availability of data and materials}

The datasets used and analyzed in the study are available on request to the corresponding author

\section{References}

[1] Bierbaum BE, Callaghan JJ, Galante JO, Rubash HE, Tooms RE, Welch RB. An analysis of blood management in patients having a total hip or knee arthroplasty. The Journal of bone and joint surgery American volume 1999;81:2-10. doi: 10.2106/00004623-199901000-00002.

[2] Callaghan JJ, O'Rourke MR, Liu SS. Blood management: issues and options. The Journal of arthroplasty 2005;20:51-4. doi: 10.1016/j.arth.2005.03.018.

[3] Sehat KR, Evans R, Newman JH. How much blood is really lost in total knee arthroplasty?. Correct blood loss management should take hidden loss into account. The Knee 2000;7:151-55. doi: 10.1016/s0968-0160(00)00047-8. 
[4] Grady-Benson JC, Oishi CS, Hanson PB, Colwell CW, Jr., Otis SM, Walker RH. Postoperative surveillance for deep venous thrombosis with duplex ultrasonography after total knee arthroplasty. The Journal of bone and joint surgery American volume 1994;76:1649-57. doi: 10.2106/00004623-199411000-00008.

[5] Stulberg BN, Insall JN, Williams GW, Ghelman B. Deep-vein thrombosis following total knee replacement. An analysis of six hundred and thirty-eight arthroplasties. The Journal of bone and joint surgery American volume 1984;66:194-201.

[6] Wang CJ, Wang JW, Weng LH, Hsu CC, Huang CC, Yu PC. Prevention of deep-vein thrombosis after total knee arthroplasty in Asian patients. Comparison of low-molecular-weight heparin and indomethacin. The Journal of bone and joint surgery American volume 2004;86:136-40. doi: 10.2106/00004623200401000-00020.

[7] Comadoll JL, Comadoll S, Hutchcraft A, Krishnan S, Farrell K, Kreuwel HT, Bechter M. Comparison of hemostatic matrix and standard hemostasis in patients undergoing primary TKA. Orthopedics 2012;35:e785-93. doi: 10.3928/01477447-20120525-14.

[8] Grosu I, Lavand'homme P, Thienpont E. Pain after knee arthroplasty: an unresolved issue. Knee surgery, sports traumatology, arthroscopy : official journal of the ESSKA 2014;22:1744-58. doi: 10.1007/s00167-013-2750-2.

[9] Kim HJ, Fraser MR, Kahn B, Lyman S, Figgie MP. The efficacy of a thrombin-based hemostatic agent in unilateral total knee arthroplasty: a randomized controlled trial. The Journal of bone and joint surgery American volume 2012;94:1160-5. doi: 10.2106/JBJS.K.00531.

[10] Watts CD, Pagnano MW. Minimising blood loss and transfusion in contemporary hip and knee arthroplasty. The Journal of bone and joint surgery British volume 2012;94:8-10. doi: 10.1302/0301620X.94B11.30618.

[11] Carson JL, Poses RM, Spence RK, Bonavita G. Severity of anaemia and operative mortality and morbidity. Lancet 1988;1:727-9. doi: 10.1016/s0140-6736(88)91536-x.

[12] Chang YL, Hung SH, Ling W, Lin HC, Li HC, Chung SD. Association between ischemic stroke and irondeficiency anemia: a population-based study. PloS one 2013;8:e82952. doi:

10.1371/journal.pone.0082952.

[13] Pereira AA, Sarnak MJ. Anemia as a risk factor for cardiovascular disease. Kidney international Supplement 2003:S32-9. doi: 10.1046/j.1523-1755.64.s87.6.x.

[14] Levine MN, Raskob G, Beyth RJ, Kearon C, Schulman S. Hemorrhagic complications of anticoagulant treatment: the Seventh ACCP Conference on Antithrombotic and Thrombolytic Therapy. Chest 2004;126:287S-310S. doi: 10.1378/chest.126.3_suppl.287S. 
[15] Shaieb MD, Watson BN, Atkinson RE. Bleeding complications with enoxaparin for deep venous thrombosis prophylaxis. The Journal of arthroplasty 1999;14:432-8. doi: 10.1016/s0883-5403(99)900980 .

[16] Benoni G, Fredin H. Fibrinolytic inhibition with tranexamic acid reduces blood loss and blood transfusion after knee arthroplasty: a prospective, randomised, double-blind study of 86 patients. The Journal of bone and joint surgery British volume 1996;78:434-40.

[17] Georgiadis AG, Muh SJ, Silverton CD, Weir RM, Laker MW. A prospective double-blind placebo controlled trial of topical tranexamic acid in total knee arthroplasty. The Journal of arthroplasty 2013;28:78-82. doi: 10.1016/j.arth.2013.03.038.

[18] Hiippala S, Strid L, Wennerstrand M, Arvela V, Mantyla S, Ylinen J, Niemela H. Tranexamic acid (Cyklokapron) reduces perioperative blood loss associated with total knee arthroplasty. British journal of anaesthesia 1995;74:534-7. doi: 10.1093/bja/74.5.534.

[19] Ishida K, Tsumura N, Kitagawa A, Hamamura S, Fukuda K, Dogaki Y, Kubo S, Matsumoto T, Matsushita T, Chin T, Iguchi T, Kurosaka M, Kuroda R. Intra-articular injection of tranexamic acid reduces not only blood loss but also knee joint swelling after total knee arthroplasty. International orthopaedics 2011;35:1639-45. doi: 10.1007/s00264-010-1205-3.

[20] Panteli M, Papakostidis C, Dahabreh Z, Giannoudis PV. Topical tranexamic acid in total knee replacement: a systematic review and meta-analysis. The Knee 2013;20:300-9. doi:

10.1016/j.knee.2013.05.014.

[21] Wong J, Abrishami A, El Beheiry H, Mahomed NN, Roderick Davey J, Gandhi R, Syed KA, Muhammad Ovais Hasan S, De Silva Y, Chung F. Topical application of tranexamic acid reduces postoperative blood loss in total knee arthroplasty: a randomized, controlled trial. The Journal of bone and joint surgery American volume 2010;92:2503-13. doi: 10.2106/JBJS.I.01518.

[22] Oz MC, Cosgrove DM, 3rd, Badduke BR, Hill JD, Flannery MR, Palumbo R, Topic N. Controlled clinical trial of a novel hemostatic agent in cardiac surgery. The Fusion Matrix Study Group. The Annals of thoracic surgery 2000;69:1376-82. doi: 10.1016/s0003-4975(00)01194-2.

[23] Testini M, Marzaioli R, Lissidini G, Lippolis A, Logoluso F, Gurrado A, Lardo D, Poli E, Piccinni G. The effectiveness of FloSeal matrix hemostatic agent in thyroid surgery: a prospective, randomized, control study. Langenbeck's archives of surgery 2009;394:837-42. doi: 10.1007/s00423-009-0497-5.

[24] Renkens KL, Jr., Payner TD, Leipzig TJ, Feuer H, Morone MA, Koers JM, Lawson KJ, Lentz R, Shuey H, Jr., Conaway GL, Andersson GB, An HS, Hickey M, Rondinone JF, Shargill NS. A multicenter, prospective, randomized trial evaluating a new hemostatic agent for spinal surgery. Spine 2001;26:1645-50. doi:

10.1097/00007632-200108010-00002. 
[25] Di Francesco A, Flamini S, Fiori F, Mastri F. Hemostatic matrix effects on blood loss after total knee arthroplasty: A randomized controlled trial. Indian journal of orthopaedics 2013;47:474-81. doi: 10.4103/0019-5413.118203.

[26] Helito CP, Gobbi RG, Castrillon LM, Hinkel BB, Pecora JR, Camanho GL. Comparison of Floseal(r) and electrocautery in hemostasis after total knee arthroplasty. Acta ortopedica brasileira 2013;21:320-2. doi: 10.1590/S1413-78522013000600004.

[27] Schwab PE, Thienpont E. Use of a haemostatic matrix does not reduce blood loss in minimally invasive total knee arthroplasty. Blood transfusion = Trasfusione del sangue 2015;13:435-41. doi: 10.2450/2015.0199-14.

[28] Suarez JC, Slotkin EM, Alvarez AM, Szubski CR, Barsoum WK, Patel PD. Prospective, randomized trial to evaluate efficacy of a thrombin-based hemostatic agent in total knee arthroplasty. The Journal of arthroplasty 2014;29:1950-5. doi: 10.1016/j.arth.2014.05.025.

[29] Yen SH, Lin PC, Chen B, Huang CC, Wang JW. Topical Tranexamic Acid Reduces Blood Loss in Minimally Invasive Total Knee Arthroplasty Receiving Rivaroxaban. BioMed research international 2017;2017:9105645. doi: 10.1155/2017/9105645.

[30] Owens WD, Felts JA, Spitznagel EL, Jr. ASA physical status classifications: a study of consistency of ratings. Anesthesiology 1978;49:239-43. doi: 10.1097/00000542-197810000-00003.

[31] Haas SB, Cook S, Beksac B. Minimally invasive total knee replacement through a mini midvastus approach: a comparative study. Clinical orthopaedics and related research 2004:68-73. doi:

10.1097/01.blo.0000147649.82883.ca.

[32] Nadler SB, Hidalgo JH, Bloch T. Prediction of blood volume in normal human adults. Surgery 1962;51:224-32.

[33] Wells PS, Anderson DR, Bormanis J, Guy F, Mitchell M, Gray L, Clement C, Robinson KS, Lewandowski $B$. Value of assessment of pretest probability of deep-vein thrombosis in clinical management. Lancet 1997;350:1795-8. doi: 10.1016/S0140-6736(97)08140-3.

[34] Rabinov K, Paulin S. Roentgen diagnosis of venous thrombosis in the leg. Archives of surgery 1972;104:134-44. doi: 10.1001/archsurg.1972.04180020014004.

[35] Gazzeri R, Galarza M, Alfier A. Safety biocompatibility of gelatin hemostatic matrix (Floseal and Surgiflo) in neurosurgical procedures. Surgical technology international 2012;22:49-54.

[36] Aguilera X, Martinez-Zapata MJ, Bosch A, Urrutia G, Gonzalez JC, Jordan M, Gich I, Maymo RM, Martinez N, Monllau JC, Celaya F, Fernandez JA. Efficacy and safety of fibrin glue and tranexamic acid to prevent postoperative blood loss in total knee arthroplasty: a randomized controlled clinical trial. The Journal of bone and joint surgery American volume 2013;95:2001-7. doi: 10.2106/JBJS.L.01182. 
[37] Schwab PE, Thienpont E. Use of a haemostatic matrix (Floseal $(\mathrm{R})$ ) does not reduce blood loss in minimally invasive total knee arthroplasty performed under continued aspirin. Blood transfusion = Trasfusione del sangue 2016;14:134-9. doi: 10.2450/2015.0023-15.

[38] Molloy DO, Archbold HA, Ogonda L, McConway J, Wilson RK, Beverland DE. Comparison of topical fibrin spray and tranexamic acid on blood loss after total knee replacement: a prospective, randomised controlled trial. The Journal of bone and joint surgery British volume 2007;89:306-9. doi: 10.1302/0301620X.89B3.17565.

[39] Sabatini L, Trecci A, Imarisio D, Uslenghi MD, Bianco G, Scagnelli R. Fibrin tissue adhesive reduces postoperative blood loss in total knee arthroplasty. Journal of orthopaedics and traumatology : official journal of the Italian Society of Orthopaedics and Traumatology 2012;13:145-51. doi: 10.1007/s10195012-0198-7.

\section{Figures}




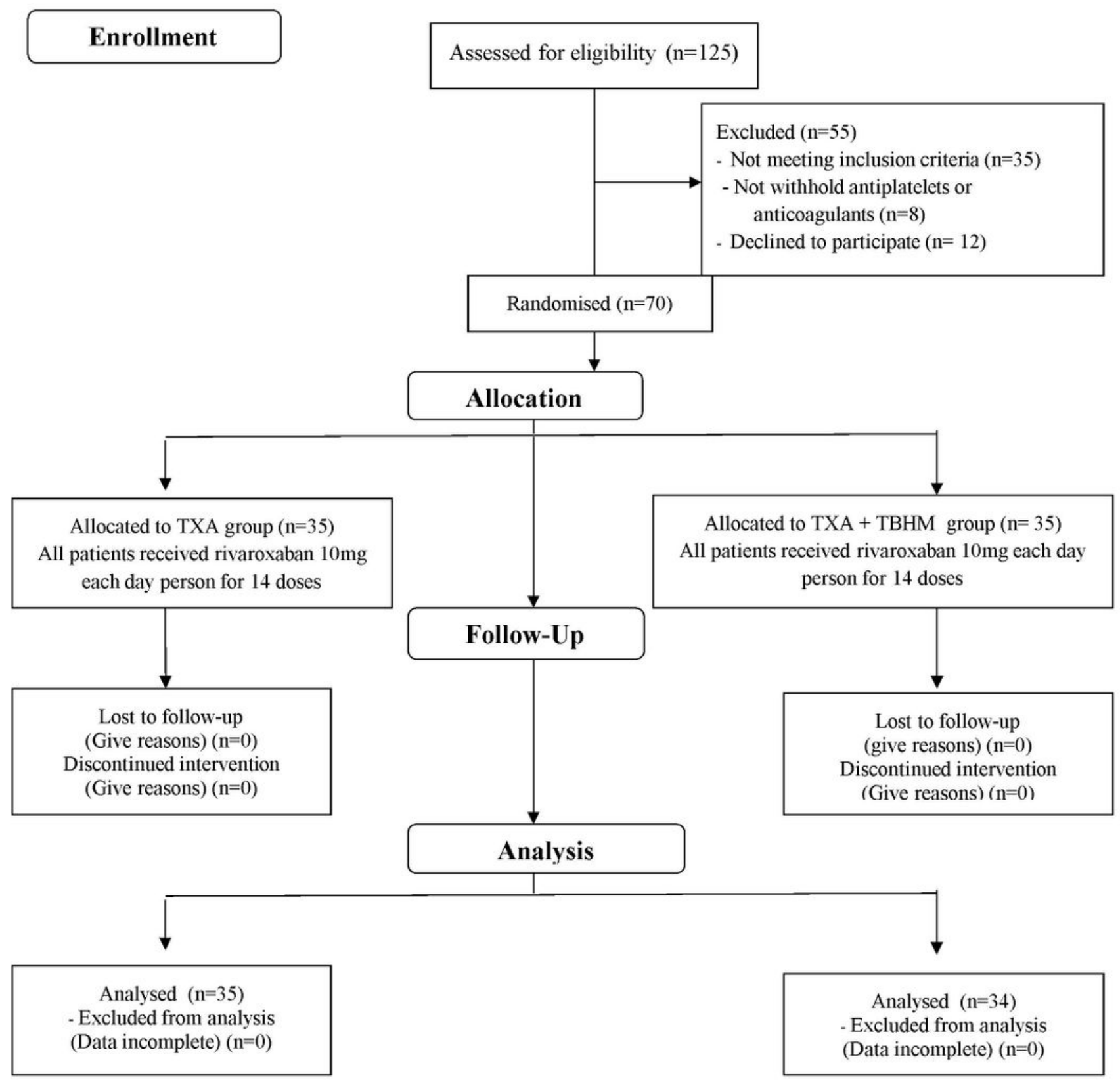

\section{Figure 1}

Flow diagram of all patients, TXA: tranexamic acid, TBHM: thrombinbased hemostatic matrix 